\title{
LA NOTA ROJA: PERIODISMO POPULAR Y TRANSICIÓN A LA DEMOCRACIA EN MÉXICO*
}

\author{
Daniel C. Hallin **
}

Fecha de recepción: enero 2000

Fecha de aceptación y versión final: abril 2000

\begin{abstract}
Resumen: Este artículo analiza el rol ambivalente de la información de sucesos en la esfera pública mexicana, señalando los sesgos de la representación mediática del crimen, la fusión que se produce entre géneros informativos y de entretenimiento, y las diferencias entre programas dirigidos a sectores sociales segmentados según su capacidad adquisitiva. Estas transformaciones son explicadas en relación a dos cambios estructurales de la sociedad mexicana: la democratización y la liberalización económica.

Palabras Clave: Medios de comunicación, televisión, información sensacionalista, prensa amarilla, democratización, liberalización económica, México.
\end{abstract}

Abstract: This article analyzes tha ambivalent role of the sections of accidents and crime reparts in the mexican public sphere, underlying the bias of crime media representation, the joining between informative section and entertainment, and the differences among programs directed to segmented social sectors according to their purchaising power. These transformations are explained in the relation to two structural changes of mexican society: the democratization and the economic liberalization.

Key Words: Mass media, television, sensacionalist information, tabloid, democratization, economic liberalization, Mexico.

El periodismo sensacionalista - la nota roja- se introdujo en la cultura mediática mexicana a mediados de la década de los '90. Su advenimiento es un complicado fenómeno histórico unido a dos profundos cambios en la sociedad y los medios mexicanos: la transición a la democracia y la liberalización económica. En la escena política, México ha tenido desde 1929 un "régimen de partido único dominante”. Los partidos de la oposición existían, pero el Partido Revolucionario Institucional (PRI) monopolizó de forma efectiva el poder político, controlando tanto el Estado como amplios sectores de la sociedad civil mexicana. La mayor parte de los medios de comunicación estaban integrados dentro del sistema "semi-autoritario", por el cual el PRI mantenía su hegemonía. El poder del partido gobernante comenzó a erosionarse a finales de los '80, como consecuencia de que candidatos de la oposición empezaran a ganar algunas elecciones locales y regionales, incrementándose la velocidad del cambio en los '90, y como resultado de la pérdida del control de la Cámara de Diputados por parte del PRI frente a los dos principales partidos de la oposición en 1997.

Simultáneamente, México se ha unido a la ola global del neoliberalismo, transitando desde el capitalismo de corte intervencionista que ha prevalecido en la mayor parte de América Latina durante este siglo, a una economía en la cual la lógica del mercado cada vez es más predominante. Este hecho afecta tanto a los medios de comunicación como a otros sectores de la economía. La prensa, que dependía anteriormente del apoyo estatal de forma significativa, ha escogido, o sido obligada a escoger, sobrevivir en el mercado paulatinamente. Por otra parte, la televisión mexicana ha sido básicamente siempre de carácter comercial. Sin embargo, una compañía concreta y prácticamente desde sus comienzos, Televisa, ha venido manteniendo un cuasimonopolio del mercado. En 1993, como parte del impulso a la privatización de empresas de titularidad pública, el Gobierno vendió una red de cadenas estatales -una insignificante parte del escenario mediático de México-, a una empresa privada, inaugurando así una nueva era de competición en la historia de la televisión mexicana. El nuevo competidor, Televisión Azteca, ha jugado un papel principal en la introducción del periodismo sensacionalista en México.

Estos dos procesos, la democratización y la liberalización, están históricamente unidos. Sin embargo, la medida en la que éstos están en harmonía o conflicto y sus implica-

* Una versión previa de este artículo ha sido publicado en Colin Sparks and John Tulloch, Eds. Tabloid Tales, 2000. Reproducido con el permiso de su editor original Rowman\&Littlefield. Traducido por Oscar García Luengo.

** Profesor de Comunicación en la Universidad de California, San Diego.凶dhallin@weber.ucsa.edu

El autor quiere expresar su agradecimiento a Raúl Trejo Delarbre, José Carlos Lozano, Chappell Lawson, Cecilia Castellanos y Andrés Villarreal por sus valiosos consejos e información. El contenido del análisis del estudio de 1994 fue hecho básicamente por Virginia Escalante. 
ciones para el periodismo y la función pública de los medios complican el análisis mediático, como también la política mexicana. Esto se configura como información esencial para el estudio de la tendencia a la "sensacionalización" del periodismo.

Personalmente, enfocaría la "sensacionalización" del periodismo de dos formas: Primero, examinando los medios sensacionalistas en el sentido estricto de la palabra, esto es, los medios donde el contenido sensacionalista es esencial, y, en siguiente lugar, considerando la medida en la que los principios de la prensa sensacionalista están transformando el periodismo tradicional en México.

\section{EL AUGE, CAÍDA Y RESURGIMIENTO DE LA NOTA ROJA}

El periodismo de corte sensacionalista es básicamente un fenómeno televisivo en México. Sin duda, noticias sobre crímenes han representado siempre una parte del periodismo de este país y el término nota roja tiene una larga historia (Monsiváis, 1997). Sin embargo, como el sur de Europa y el resto de América Latina, México no ha sido nunca un país donde se haya consumido prensa de forma masiva. Los periódicos mexicanos tienen una distribución limitada, y se puede decir que su circulación se focaliza en las élites. Lo más parecido a un periódico de consumo masivo lo constituye La Prensa, un diario de la Ciudad de México, aunque tener una tirada de 100.000 ejemplares (Trejo Delarbre, 1990) en una ciudad de 20 millones de habitantes, no tiene demasiada importancia. México tiene asimismo semanales sensacionalistas como ;Alarma!, el cual ofrece un tipo de violencia obscena, como historias sobre atentados y, sobre todo, impactantes fotografías de cuerpos que han sido víctimas de accidentes o crímenes. La audiencia de estas publicaciones está constituida por varones de clase trabajadora, pese a que este grupo no es un fuerte consumidor de prensa escrita en México.

La audiencia real de la nota roja se concentra en los telespectadores. La novedad más significativa fue la emisión de Ciudad Desnuda por parte de Televisión Azteca en 1995. Ciudad Desnuda, cuya principal materia prima eran los crímenes callejeros que asolaban la Ciudad de México, se constituyó como uno de los primeros éxitos de la cadena televisiva, subiendo hasta el $20 \%$ en el índice rating hasta el $30 \%$ en el share, antes de que Televisa introdujese un competidor, Fuera de la Ley, y llevase a Ciudad Desnuda de vuelta a posiciones más modestas (Moreno Maldonado, 1997).

Los dos programas generaron una gran polémica, y periodistas, intelectuales, organizaciones civiles, anunciantes y políticos -incluyendo al Presidente de México-, los criticaron y calificaron de irresponsables (Vela González, 1997; Trejo Delarbre, 1997; Galán, 1997). La mayoría culpó a estos programas de contribuir a empeorar el problema del crimen, al impulsar la cultura de violencia, aunque algunos desde la izquierda los inculparon, probablemente con más argumentos, de promover una ideología política de corte autoritaria. En noviembre de 1997, ambas compañías de televisión cedieron ante las presiones y cancelaron la emisión de los programas. Este resultado produjo reacciones contradictorias; algunos comentaristas celebraban el fracaso de los principales impulsores de la nota roja, al mismo tiempo que se preocupaban de que la presión del Presidente había sido decisiva, demostrándose que los medios de comunicación se doblegaban todavía ante la autoridad política.

Cualquiera que sea el peso relativo de cada una de las fuerzas que criticaron Ciudad Desnuda y Fuera de la Ley, esta interpretación se prueba infundada. Éstos no eran los únicos programas sensacionalistas que se retransmitían, pero sí los más representativos. Un estudio aseguraba que, en el año 1996, se emitían en la Ciudad de México 31 horas a la semana de programas sobre violencia basados en hechos reales, incluyendo Primer Impacto, programa sensacionalista producido por Univisión, red hispanohablante estadounidense ligada a Televisa (Fadul, Solís \& FernándezChristlieb, 1996). Al poco tiempo, Ciudad Desnuda y Fuera de la Ley fueron reemplazados por programas básicamente similares. México nunca ha tenido una regulación fuerte sobre televisión. Se consintió a Televisa perseguir sus intereses económicos sin obstáculos, y ésta devolvió el favor otorgando apoyo político al Gobierno. Asimismo, se evitó la emisión de programas que podrían haber provocado controversia política y haber tentado al Gobierno a intervenir directamente; no había ninguna razón por la que arriesgarse cuando la compañía gozaba de un monopolio. Hoy, con un mercado televisivo más competitivo y siendo mayor la inhibición en contra de la intervención presidencial, la lógica del mercado es la dominante.

El sustituto de Fuera de la Ley en Televisa fue Duro y Directo, el cual apareció todas las noches durante una hora y media en uno de los cuatro canales de dicha empresa; mientras tanto Televisión Azteca introdujo Visión Urbana, programa emitido en su canal principal durante una hora todas las noches. Ambos son considerados como clásicos dentro de la televisión sensacionalista, y básicamente se centran en crímenes callejeros, con ritmos rápidos, tonos sofocantes, imágenes dramáticas y altos niveles emotivos; a diario encontramos un nuevo suministro de "espantosos crímenes", "ríos de sangre" y "bajas pasiones". El sensacionalismo mexicano está centrado de forma más exclusiva en crímenes callejeros y accidentes que el sensacionalismo de otros países, prestando poca atención a historias de interés humano. Duro y Directo incluye ocasionalmente un reportaje para la orientación del consumidor, como por ejemplo, la cobertura de un acuerdo entre el Gobierno y los comerciantes de ultramarinos para contener los precios de los comestibles de primera necesidad. También incluye regularmente secciones sobre deportes y ocio (a veces insertando otros capítulos culturales de Televisa), horóscopos y un apartado acerca de animales, el cual contiene una parte donde aparece un payaso que responde a las llamadas de los telespectadores para ayudar a animales con problemas, una crónica diaria llamada Pasarela de Mascotas, en la cual se muestran perros jugando al fútbol y cosas del género, e historias ocasionales sobre fauna del zoo, mascotas exóticas o maltrato de animales. No obstante, en la mayor parte de Duro y Directo se suceden robos de bancos, atracos a taxistas o casos de niños robados. 
Visión Urbana es un programa algo más sofisticado y con una agenda más amplia, probablemente como consecuencia de que Televisión Azteca ha puesto su objetivo en una audiencia más cualificada intelectualmente y adinerada. El crimen callejero es todavía el centro del programa, pero aquí no hay horóscopos de ningún tipo ni Pasarela de Mascotas, y existe más cobertura sobre la vida urbana más allá del crimen callejero; Visión Urbana está en este sentido entre un informativo estándar y una revista sensacionalista de corte estadounidense, con contenidos más centrados en los asuntos públicos más tradicionales que en espectáculos como Hard Copy o Inside Edition. La emisión del 13 de enero de 1999, por ejemplo, comenzó con relatos acerca de la huelga del profesorado (enfatizando los inconvenientes para los ciudadanos en general), de las restricciones al tráfico ocasionadas por la contaminación atmosférica, del cierre de una clínica de la Cruz Roja en la Ciudad de México a causa de un recorte presupuestario, de una huelga de tránsito, de las quejas planteadas por policías sobre el injusto tratamiento que reciben de sus superiores, y del plan del Ministerio de Seguridad Pública para entrenar a civiles en tareas de seguridad pública. Es entonces cuando las historias sobre crímenes empiezan.

Los dos programas se presentaban como defensores del ciudadano corriente, y fomentaban la participación de los telespectadores, facilitando frecuentemente una serie de números de teléfono donde podían denunciar fechorías. Además, ambos, aunque Duro y Directo de forma más latente, se presentaban como paladines de la ley y el orden, como combatientes del crimen, reclamando a veces mano dura para erradicarlo. Sin ningún lugar a dudas, esto se produce en parte como reacción a que se les acusaba de explotar el crimen con objetivos comerciales y de incentivarlo mediante su propaganda. "Duro y Directo contra la delincuencia" declaraba un eslogan, mientras que los reportajes sobre arrestos de sospechosos son normalmente seguidos de requerimiento de colaboración ciudadana para facilitar información que pueda ayudar a condenarlos, acompañándolo con imágenes gráficas y la palabra "denúncielo". En otras ocasiones, una serie de fotografías de sospechosos viene seguida de la imagen digital de una puerta de una celda cerrándose de golpe, incluyéndose frases como "robo con violencia, basta 18 años de cárcel". Un alto porcentaje de los casos conlleva el arresto de sospechosos, porque sin duda éstas proporcionan mucha más información sobre los mismos, que sobre los concernientes a crímenes no resueltos. Este hecho implica que el sensacionalismo tergiversa drásticamente la realidad en un sentido importante: la mayoría de los crímenes que aparecen en la televisión son resueltos, mientras que en la realidad, y siguiendo a Ruiz Harrell (1999, 61), sólo fueron arrestados un 2.5\% de los sospechosos de haber cometido los crímenes contabilizados por la fiscalía de la Ciudad de México en 1995.

Paralelamente a que Cindad Desnuda y Fuera de la Ley fueran suprimidos de antena, Sergio Sarmiento (1997), un destacado cronista que se convirtió en un directivo de Televisión Azteca y contribuyó a crear Ciudad Desnuda, ofrecía el siguiente análisis de las posturas enfrentadas:

\begin{abstract}
A la clase media no le gusta ver en su pantalla imágenes desagradables, rostros morenos, pobreza o crí menes. Para la clase media la televisión debe ser inspiracional, debe contener programas culturales y educativos, rostros blancos y cabelleras rubias. Los políticos, miembros de esa clase media, quieren verse a si mismos en la televisión todas las noches. Para ellos los programas informativos deben concentrarse en inauguraciones de obras publicas y en discursos. No entienden por qué los noticiarios deban referirse al crimen, al sufrimiento y a otros temas desagradables.
\end{abstract}

Esto, por supuesto, tiene que ver con el reclamo postmodernista (Fiske, 1992), el cual asegura que el periodismo sensacionalista representa un triunfo de lo popular sobre la cultura de la élite. Es indudablemente cierto que la gente corriente, incluyendo a los pobres, aparecen con más frecuencia en los programas televisivos sensacionalistas que en las noticias tradicionales. En cualquier caso, esto no conlleva la justificación de estos programas. El programa brasileño Aqui Agora, también clasificado dentro de este grupo de emisiones, ha tenido a veces una cobertura significativa de temas como movimientos políticos en comunidades pobres (Epstein, 1993; Bucci, 1993). El sensacionalismo televisivo en México no presenta nada de esto y, ciertamente, no informa sobre miserias. Se centra más intensamente en el crimen, y su orientación hacia la ley y el orden implica que, aunque las víctimas obtienen una atención pública (Imagen 1), una alta proporción de los "rostros morenos" que aparecen en las pantallas son los de aquellos sospechosos presentados para divulgar su humillación (Imagen 2). Por supuesto, la violencia no es el único asunto que importa en la vida de la Ciudad de México, y sería más riguroso establecer, como uno de los legisladores de esta ciudad introdujo en el debate existente sobre Ciudad Desnuda y Fuera de la Ley, que los programas sensacionalistas implican básicamente a "yuppies" que se aprovechan de las comunidades más pobres, cuyos problemas reales desconocen prácticamente (Servicio Universal de Noticias, 1997).

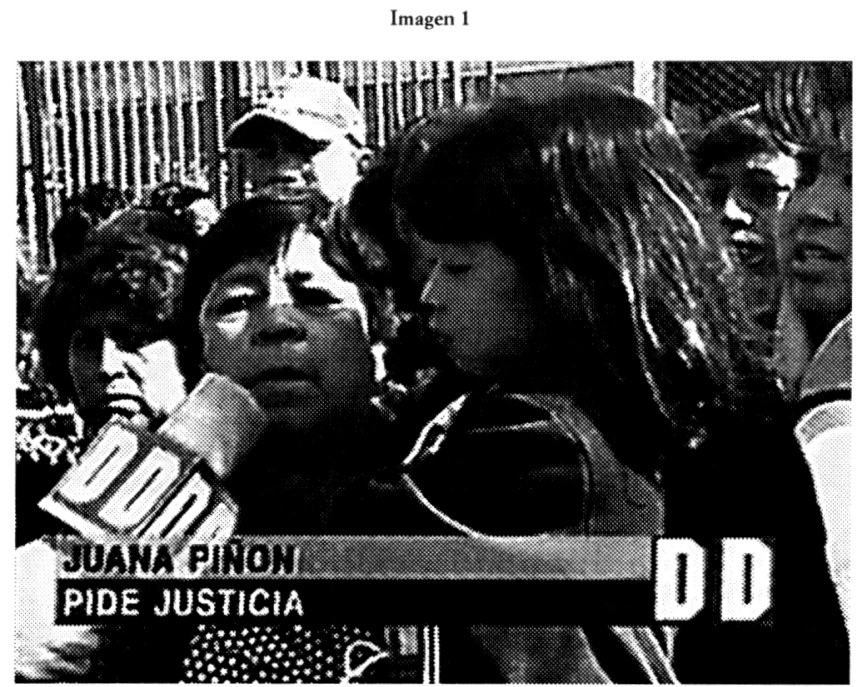

Una víctima pide justicia en Duro y Directo 


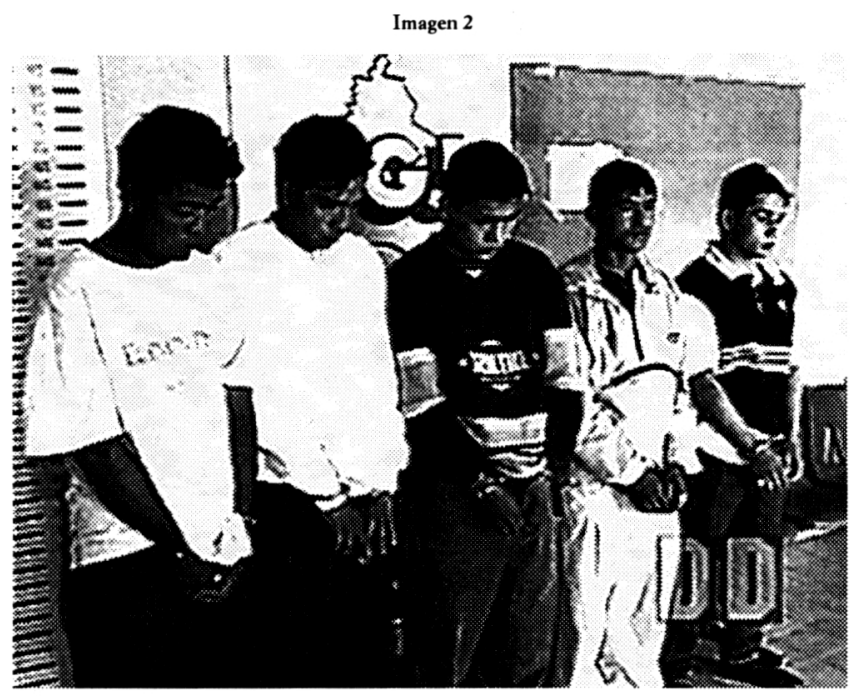

Sospechosos son capturados ante las Cámaras de Duro y Directo

\section{INFORMATIVOS TRADICIONALES: DESPOLITIZACIÓN O DEMOCRATIZACIÓN}

Los programas tradicionales de telenoticias presentan una tendencia hacia la "sensacionalización". Gran parte de los aspectos y sensibilidades de los espectáculos sensacionalistas, como impactantes titulares, efectos sonoros, dramáticas narraciones, reconstrucciones, planos a cámara lenta y condenas morales a sospechosos por parte de los periodistas, han sido trasladados a los espacios más prestigiosos. Sin embargo, los cambios de concepción son frecuentes y las dos cadenas tratan de establecer nuevas formas de periodismo y una nueva relación con su audiencia. Entre la mitad de 1998 y principios de 1999, Televisa y Televisión Azteca han moderado algunos de los rasgos sensacionalistas de sus noticiarios, como consecuencia de la renovación producida por la crítica del público. Ambas fueron acusadas de dedicar mucho tiempo a entrevistas con el secuestrador "Mochaorejas" (nombre proveniente de la costumbre del sujeto a cortar las orejas de sus víctimas), que fue capturado en agosto de 1.998. Los análisis de mercado de estas empresas mostraban también la resistencia del público a la sensacionalización (Barrera, 1999).

Tabla 14.1 Tiempo dedicado a los temas más importantes en los noticieros de la televisión mexicana (sólo cuestion es in ternas)

\begin{tabular}{|c|c|c|}
\hline & 1994 & 1998999 \\
\hline Presidente & $\begin{array}{l}\% \\
9.3\end{array}$ & $\begin{array}{l}\% \\
4.2\end{array}$ \\
\hline Ministerios, otro gobiemo foderal & 11.3 & 8.7 \\
\hline Legisla tura & 2.2 & 4.2 \\
\hline Partido, Elecciones & 30.9 & 3.5 \\
\hline Estado, gobie mo local & 0.6 & 6.7 \\
\hline Corrupcion of icial, de rechos humanos & & 3.1 \\
\hline Programas sociales & 0.4 & 1.9 \\
\hline Protestas & 1.1 & 2.1 \\
\hline Chiapas, Guerri llas & 10.7 & 0.2 \\
\hline Total pol iticas & 66.8 & 34.6 \\
\hline Economia & 4.2 & 10.2 \\
\hline Asuntos urbanos de ciudad de México & $\cdot$ & 3.6 \\
\hline Crimen, seguridad & 4.7 & 21.7 \\
\hline Asesinato de Colosio & 4.3 & \\
\hline Accidentes & 3.2 & 1.1 \\
\hline Desastres natura les & 0.3 & \\
\hline Salud & 0.2 & 5.2 \\
\hline Educación & 0.3 & 1.1 \\
\hline $\begin{array}{l}\text { Iglesia, religión } \\
\end{array}$ & 2.2 & 4.6 \\
\hline Medio ambiente & 0.4 & 2.6 \\
\hline Interés humano & & 1.0 \\
\hline $\begin{array}{l}\text { Alta cultura } \\
\end{array}$ & 3.3 & 1.1 \\
\hline Medios de Comunicación, entretenimiento & 4.4 & 2.8 \\
\hline Otros & 5.7 & 4.7 \\
\hline
\end{tabular}

No obstante, los contenidos sensacionalistas han hecho una importante incursión en el tradicional periodismo televisivo. La Tabla 1 muestra la distribución del tiempo dedicado a los diferentes asuntos en la televisión, usando como base una muestra aleatoria de 10 informativos, emitidos entre agosto de 1998 y enero de 1999; 5 de Noticiero con Guillermo Ortega (Televisa) y 5 de Hechos (Televisión Azteca), ambos paradigmáticos espacios. El resultado de este pequeño estudio está contrastado con otros de mayor calado sobre Televisa realizados en la primera mitad de 1994, acerca de sus principales noticiarios (Hallin, 1994). La diferencia más latente se refiere a la caída dramática de la cobertura de asuntos políticos, del casi $70 \%$ en noticias nacionales (excluyendo deportes) en 1994, al 35\% aproximadamente en 1998/99. Mientras tanto las noticias referentes al crimen y a la seguridad saltaron del $4.7 \%$ en 1994 (o $9 \%$ si incluimos la extensa cobertura realizada sobre el asesinato del candidato presidencial del partido en el Gobierno en ese mismo año), al $21.7 \%$ en 1998/99. Las cuestiones económicas, muchas de ellas centradas en los precios de los bienes de primera necesidad como las tortillas, también crecieron del $4.2 \%$ al $10.2 \%$, como asimismo lo hicieron otras formas de noticias no políticas: salud, desastres naturales y asuntos urbanos de la Cuidad de México, los cuales incluían temas como el aparcamiento, el tráfico y la regulación de los vendedores ambulantes.

Los dos periodos contrastados no son muy adecuados, pero son usados porque no hay otros datos disponibles. En el año 1994, ocurrieron dos hechos que con toda seguridad exageraron el índice de cobertura de asuntos políticos: se trata de la celebración de elecciones presidenciales y de la rebelión del Ejército Zapatista de Liberación Nacional en Chiapas. Pero aunque eliminemos ambos sucesos del estudio de 1994, la cobertura política llega casi al 50\% de las noticias nacionales de este año, mientras que el tratamiento del crimen, excluyendo el asesinato de Colosio, representa menos del $7 \%$.

Si la sensacionalización se centra en la "experiencia inmediata del individuo", como Sparks (1988) propone, la televisión mexicana se ha desplazado en este sentido claramente hacia el estilo sensacionalista. Como ejemplo podemos resaltar la presentación del principal relato de las noticias nocturnas del 13 de agosto de 1998 en Televisa:

Esta mañana el Valle de México vivió uno de los días mas terribles que se recuerden. Unos cuantos taxistas y microbuseros del Estado de México bloquearon trece puntos de acceso al Distrito Federal y crearon el peor caos vial que ha vivido el capital en toda su historia. Cientos de miles de personas quedaron literalmente secuestradas por un puñado de taxistas. Del enojo a la rabia; y de la rabia a la desesperación. Y la autoridad brilló por su ausencia.

El reportaje fue seguido de algunas entrevistas con enfadados conductores bloqueados en el atasco, y terminó con la entrevista del gobernador del Estado de México, sobre la que nos volveremos a referir. Por supuesto, el epicentro de la historia lo representaba la reacción emotiva de los conductores afectados. 
Una interpretación común de la sensacionalización o, para decirlo de forma más precisa, del cambio hacia el periodismo puramente movido por la lógica del mercado, atañe a la degradación o merma de la democracia causada por expulsar el debate e información políticos fuera de los medios, reemplazándolos por asuntos de la vida privada (Sparks, 1988). Esta clase de periodismo popular, se puede argumentar, podría proporcionar una desviación inofensiva o información útil para las cuestiones privadas de la audiencia, o podría promover la cultura del miedo, de la violencia y la alienación. Lo que rotundamente no hace es facilitar la implicación de los ciudadanos en los asuntos públicos.

Por supuesto, encontramos una importante discusión alrededor de dónde se debería dibujar la línea para separar lo público de lo privado. Sin embargo, se debe tener en cuenta que desde el punto de vista político adquiere gran importancia la cuestión de que las fuerzas del mercado aparten lo político del contenido de las noticias, particularmente en una sociedad donde el sistema político democrático está emergiendo. El dueño de Televisión Azteca, tras comprar dicha cadena, respondió brevemente a la pregunta sobre el papel que creía que la empresa podría jugar en el proceso de democratización del país, asegurando que no debería jugar ninguno: "la televisión es un medio de entretenimiento y esparcimiento", dijo (Ortega Pizzaro, 1993: 6), provocando así el miedo de algunos mexicanos, preocupados por el hecho de que el mercado podría privar a la democracia incipiente del acceso a lo que es rotundamente el más importante medio de comunicación pública en México.

Aparentemente, el caso mexicano parecería poder confirmar la hipótesis de la despolitización: desde que surgió en México un mercado competitivo en el mundo de la televisión, las experiencias individuales se han colocado paulatinamente en el centro de la definición de las noticias, y la cobertura de lo político ha descendido de forma manifiesta. Sin embargo, es demasiado simplista llegar a la conclusión de que el tránsito hacia modos más populares de periodismo en este país significa nada más que despolitización. El sistema mediático mexicano es mucho más abierto y democrático en algunos sentidos de lo que lo fue a principio de los '90, y las implicaciones entre la democracia y los cambios producidos en los informativos televisivos parecen bastante complejas. El alto grado de contenidos políticos incluido en las noticias mexicanas en el periodo anterior, no implicaba la existencia de un sistema de comunicación democrático. Por el contrario, reflejaba el hecho de que los noticiarios estaban básicamente orientados al apoyo estatal $\mathrm{y}$ al respaldo del partido en el poder. Esto no era exclusivo de la televisión. Los periódicos tenían muy pocos lectores, dependían de forma significativa de los pagos oficiales recibidos a cambio de la propaganda favorable y, con más bien pocas excepciones, estaban más dirigidos al consumo por parte de los gabinetes de prensa gubernamentales que para el público en general 1 . El departamento de informativos de Televisa, mientras tanto, ha sido considerado en la mayor parte de su vida como el "ministerio oficial de información". Su propietario se describió a sí mismo como un "soldado" del partido gobernante, siendo bastante comunes las llamadas telefónicas entre este departamento y la oficina de la Presidencia o la Secretaría de la Gobernación, para considerar el tratamiento de historias sensibles (Hallin, próxima publicación; Lawson, 1999; Delgado, 1998; González Molina, 1987; Trejo Delarbre, 1985, 1988).

Los Informativos de Televisa eran claramente deferentes al Gobierno y a los miembros del partido, y se centraban en sus actividades de forma extrema. Esto era, en muchos aspectos, un elemento que encajaba mal en una empresa de televisión cuyos objetivos eran comerciales; tenía ingredientes específicos de la cultura de la televisión comercial, como amplios reportajes deportivos, frecuente propaganda de otras ofertas de entretenimiento de Televisa, un buen número de historias visuales casi todos los días, e incursiones ocasionales en un tipo de populismo retórico, a veces nacionalista en esencia, el cual había sido parte de la cultura oficial desde que la revolución mexicana fuera "institucionalizada". Sin embargo, mucho de esto, consistente en largos discursos de los miembros del Gobierno, comunicados oficiales leídos palabra por palabra, listas de nombramientos a puestos oficiales y cosas del género, tuvo poco interés popular.

El ciudadano de a pie jugó un papel muy limitado, y claramente subordinado, en la ilustración de la sociedad y política mexicanas llevada a cabo por Televisa. La mayoría aparecía a veces como representaciones del sistema clientelar, por el cual el Gobierno repartía beneficios entre grupos seleccionados de ciudadanos como premio a su lealtad política. Una de las imágenes más comunes encontradas en la muestra del estudio de 1994 citado con anterioridad, era la del Presidente hablando ante un grupo de campesinos quienes se sentaban silenciosamente y aplaudían, tras lo cual eran premiados con terrenos u otros beneficios gubernamentales. Televisa, de vez en cuando, se presentaba en los términos de la misma relación con sus propios clientes. A principios de enero de 1994, por ejemplo, podíamos ver un relato en el cual el director y presentador de los informativos, Jacobo Zabludovsky, aparecía en su propio programa para homenajear a una anciana voceadora (vendedora de periódicos) de 95 años, la cual había estado vendiendo durante más de 20 años la edición nocturna de Ovaciones, un periódico de Televisa, en las nebulosas calles de la Ciudad de México. Doña Nati, como Zabludovsky se refería a ella, denunció que ella estaba avergonzada por su apariencia y no quería aparecer en televisión (Imagen 3), pero él siguió adelante con la entrevista y, en el programa del día siguiente, se mostraba a un grupo de trabajadores de Televisa entregando a la anciana en su casa un enorme equipo de televisión que casi llenaba los 9 metros cuadrados de su vivienda. De varias formas, este tipo de historias salía con más o menos frecuencia en las emisiones de Televisa, donde se mostraban imágenes de la trabajadora, que sufrían serios problemas desde hacía tiempo, recibiendo agradecida de las benévolas autoridades los premios por su paciencia. Doña Nati explicaba que ella seguiría trabajando indefinidamen-

1. Sus fotografías típicas, por ejemplo, representan a funcionarios en podios o reuniones (Wallen, 1998). 
te porque necesitaba pagar el alquiler; ¿Por qué no tenía una pensión?, Televisa nunca lo preguntó.

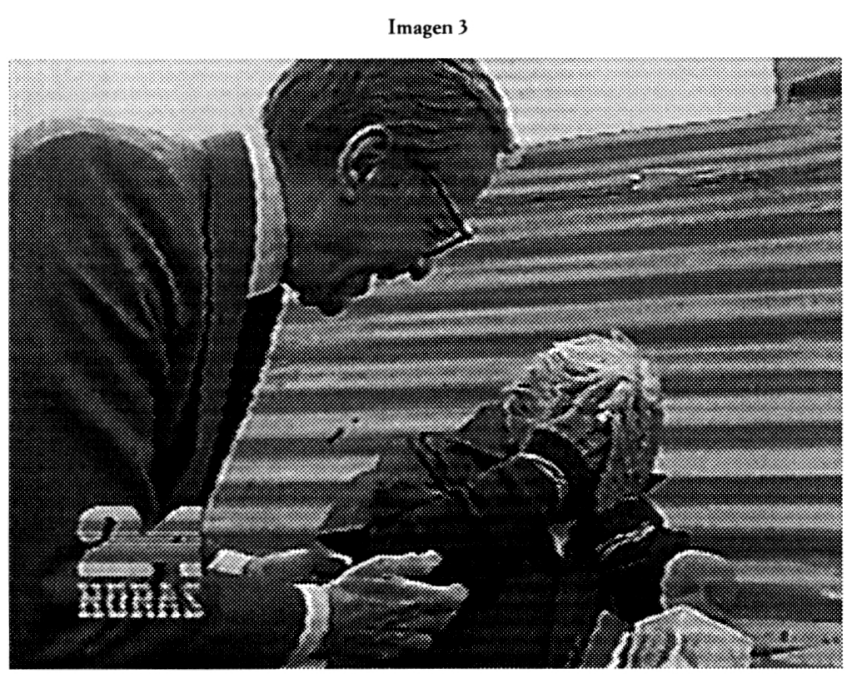

Jacobo Zabludovsky entrevista a la reacia "Doña Nati"

En otras ocasiones, gente corriente aparecía en las pantallas para apoyar la propia posición política de Televisa. Durante la rebelión en Chiapas, por ejemplo, Televisa dependió exclusivamente de declaraciones oficiales durante algunos días, pero entonces empezó a tener en cuenta a los campesinos aliados al Gobierno para denunciar a los rebeldes. A veces también se mostraba a gente común exigiendo la ley y el orden, un asunto que había defendido, en menor grado, incluso antes de la explosión de la nota roja. La mayor parte del tiempo, la gente corriente aparecía en las noticias de la televisión mexicana en un plano secundario y subordinado, y, en este sentido, éstas reflejaban una cultura política autoritaria.

En los últimos años, Televisa se ha enfrentado a fuertes presiones para que se distanciase del viejo orden político, incluyendo denuncias y manifestaciones políticas, presiones surgidas de negociaciones entre el partido en el Gobierno y los de la oposición alrededor de las reglas de la competición electoral, y la presión competitiva de Televisión Azteca, la cual, a pesar de la timidez política de su propietario, impulsó la aparición de una audiencia enfadada con la afinidad política de su rival. Los cambios en Televisa fueron acelerados por la muerte de su propietario en 1997, y se culminó en enero de 1998 con el despido del presentador Zabludovsky y la substitución de su paradigmático programa 24 Horas. Los informativos mexicanos son hoy mucho más abiertos políticamente, sobre todo en el sentido de que da mucha más cobertura a los partidos de la oposición. Esto queda reflejado de alguna forma en los datos contenidos en la Tabla 1, donde podemos observar la disminución de la cobertura del Presidente y el crecimiento de la cobertura del poder legislativo (donde en 1997 el partido en el Gobierno perdió su mayoría en la cámara baja), y de los Gobiernos locales y regionales. Gran parte de la cobertura de esto último se centra en la Asamblea Legislativa del Distrito Federal, donde los partidos de la oposición ostentan la mayoría.
El cambio hacia unos informativos televisivos más orientados a lo popular en México se interpreta mejor como un producto combinado por la democratización y el aumento de la competición comercial, por un lado, y por implicaciones políticas igualmente complejas, por otro. Citando a Sparks otra vez (1988), el hecho de que la experiencia de la gente común es cada vez más "la principal fuente de evidencia y valía” en los noticiarios, podría constituir un importante símbolo del tránsito a la cultura política democrática 2. En la muestra de 1998/99, los ciudadanos de a pie (sin incluir a policías ni ladrones) integraban el $30 \%$ de aquellos que hablaban ante las cámaras, o, si lo medimos en relación con el tiempo más que el número de apariciones, poco más del 20\%. Si comparamos estos datos con los del 1994, los porcentajes son de un $12 \%$ de apariciones, y un $5.6 \%$ en términos de tiempo en antena. En algunos casos, por supuesto, la gente común aparece sólo en el plano privado, fuera del mundo político. Pero en otras muchas ocasiones, su aparición en relación con cuestiones políticas expresa su enfado con las autoridades públicas, las cuales fracasan en asuntos que les conciernen directamente. La propia presentación en este sentido, parece constituir un importante cambio en la representación política realizada por los medios mexicanos.

La pasión por la vox populi (opinión popular) en la televisión mexicana va más allá de los noticiarios nocturnos hoy en día. Por ejemplo, Televisa emite a veces un programa informativo titulado Testigos, el cual pone mucho énfasis en la opinión del pueblo. También produce un programa de entretenimiento llamado Picardía Mexicana, un concurso patrocinado por el Banco Bilbao Vizcaya (constantemente en medio de los festejos), en el cual los telespectadores escriben letras para melodías de música pop que centran en sus quejas sobre la sociedad. Actores de Televisa ponen en escena 3 de estas canciones en cada emisión, cada una de ellas precedidas de entrevistas dirigidas por un periodista-marioneta a gente de la calle sobre el tema en cuestión. Los asistentes en el estudio votan la mejor canción. Algunas de ellas se centran en aspectos de la vida privada, como los concernientes a las suegras y este tipo de temas, pero muchos de ellos aluden a temas expresamente políticos; policías que acosan a jóvenes, políticos que hablan mucho pero son incapaces de resolver nada, y desempleo (Imagen 4). Una canción dice sobre lo último, "Dicen los empresarios, no podemos arriesgarlo, amamos la patria, pero más amamos el dinero”.

2. Lawson (1999) en un análisis de contenido de los informativos de Televisa desde 1988 a 1996, encontró que la aparición de los portavoces oficiales (tanto del Gobierno como del partido en el poder), cayó de un 60\%, antes de la llegada de Televisión Azteca en 1993, al 40\% después. 


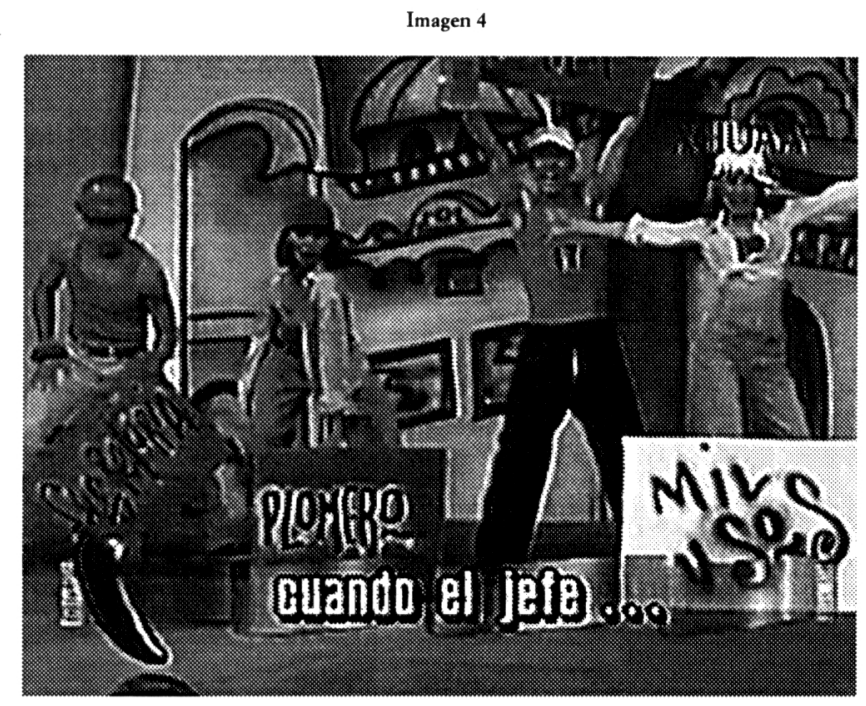

"Cuando el jefe ... llama para despedirte." Picardia Mexicana representa una escena donde cerca de la Catedral Metropolitana de la Ciudad de México, trabajadores desempleados sostienen las pancartas de sus asociaciones

Mientras tanto, los periodistas se mostraban a sí mismos cada vez más como representantes del público y, de vez en cuando, adoptaban una actitud contendiente hacia los miembros del Gobierno, legitimados por la autoridad derivada de esa función "representativa" que reclamaban. De esta forma, el presentador de Televisa, el día que los taxistas bloquearon los puntos de entrada a la Ciudad de México, introdujo su entrevista con el Gobernador del Estado de México, el cual rodea la capital, en la cual se le increpaba en representación de los ciudadanos por haber fracasado en el intento de disolver el bloqueo, adoptando el esquema "el pueblo contra el poder político” descrito por Klein (1998). Esto implicaba un cambio impresionante en relación con el trato deferente que Zabludovsky había mostrado en entrevistas similares hechas en las décadas anteriores.

El 12 de enero de 1999, por poner otro ejemplo, Televisión Azteca incluyó en su emisión las declaraciones del Secretario de Gobernación, en las cuales aseguraba que el crimen sería erradicado en México en 1999. Durante años se había establecido como una práctica habitual entre los reporteros mexicanos exponer simplemente el resumen de los argumentos oficiales, sin incluir ningún tipo de interpretación ni desconfianza. En este caso, los reporteros de Televisión Azteca presentaban un análisis, generalmente en tono escéptico, sobre la efectividad de las políticas gubernamentales de seguridad durante el año anterior, apuntando la importancia del asunto para las ambiciones presidenciales del Secretario. Luego, se pasaba a una parte que podría etiquetarse bajo la denominación de vox populi, donde la gente era preguntada sobre si se sentía segura en la Ciudad de México, y, finalmente, se incluía la historia del asalto a un banco la cual, "mas allá de las buenas intenciones y de las declaraciones de las autoridades", colocaba a la ciudad a un paso de superar el récord vigente en este tipo de delitos. El 25 de abril de 1994, por el contrario, cuando el entonces Presidente Salinas designó al director de la nueva agencia de seguridad, Zabludovsky presento la historia de la siguiente forma:
La institución que hoy nace es una especia de superprocuraduría del tamaño que la sociedad ha reclamado ante el desafío creciente del delito y de la violencia. El Presidente Salinas responde así a un reclamo público, un reclamo de la sociedad. Para luchar a fondo contra la impunidad, contra el crimen organizado... La presencia del Lic. Arsenio Farrel como coordinador es una garantía..

Una impresionante bibliografía del citado individuo se presentó después; los ciudadanos de a pie no aparecían.

Al mismo tiempo, el tránsito al mercado del periodismo popular tiene muchos elementos que impiden el desarrollo de una cultura política democrática. Encontramos el potencial de distorsionar la agenda política. Más del 20\% de las noticias son dedicadas al crimen (y este dato no incluye las historias políticas relacionadas con el asunto); es una cifra muy alta. Hoy en día se debe reconocer que el crimen es una importante cuestión pública en México. Los departamentos de Policía son ineficaces y están infectados por la corrupción, siendo el nivel de inseguridad ciudadana muy alto, aun cuando los periodistas más serios otorgan una significativa atención al asunto. El semanal de Tijuana Zeta, por ejemplo, altamente respetado por su periodismo de investigación, está centrado sobre todo en los vínculos entre el crimen organizado y los grandes intereses en Baja California, y encaja abundantes historias sensacionalistas sobre el crimen a lo largo y ancho de sus páginas, pese a que Zeta analiza el crimen como una estructura social, más que la simple presentación del mismo como sucesión de crímenes, como los medios sensacionalistas hacen. Sin embargo, y a pesar de ser el crimen una cuestión pública legítima, si consideramos que en las 10 emisiones de nuestra muestra de 1998/99 no encontramos una sola historia sobre el desempleo, ni virtualmente nada sobre cuestiones laborales ni comunidades agrícolas, está claro que existe un gran problema en relación con la agenda de los informativos.

El estilo sensacionalista también impulsa el espectro de la demagogia. Expulsa a los periodistas fuera de una concepción ética y de neutralidad, y los incentiva a presentarse a sí mismos como portavoces de la sociedad entera, contrarios a los enemigos de ésta, ya sean criminales, perezosos políticos o el insignificante puñado de taxistas tan denunciados por los periodistas de Televisa por su bloqueo; los movimientos sociales en México, como los políticos, tienen mucho que aprender sobre el modo de operar en un espacio donde la opinión pública es el centro del proceso político (Televisa mostró una y otra vez a los taxistas jugando al fútbol en las carreteras cortadas). Esto propicia las condiciones para que el periodismo contribuya a la polarización social. Además, el esquema "el pueblo contra el poder político", las acusaciones a los políticos de no hacer nada, combinadas con el llamamiento para emplear mano dura contra el crimen y el desorden, parecen potencialmente peligrosas en una sociedad donde el apoyo al proceso democrático no tiene unas profundas raíces (Craig \& Cornelius, 1981); como Sparks (1992) apuntaba, el autoritarismo populista es una forma común de periodismo sensacionalista. Este peligro fue dramatizado en junio de 1999, cuando un popular humorista de la televisión 
fue matado a tiros en la Ciudad de México, y ambas compañías televisivas presentaron horas de cobertura altamente sensacionalizada, dedicadas en su mayoría a atacar abiertamente y estrepitosamente al alcalde de izquierdas. El propietario de Televisión Azteca tomó las ondas para sugerir que el asesinato probaba que las instituciones democráticas no eran útiles (Levario Turcott, 1999). Los emisores se pusieron luego a la defensiva cuando las evidencias sugerían que el homicidio podía estar vinculado con el mundo de las drogas.

Otro problema del periodismo popular tiene que ver con las voces y experiencias "populares" que serán el centro de atención. La realidad económica de los medios a veces inclina la balanza a favor de la panorámica de la audiencia de clase media, la más valorada por los que se anuncian, y esto quizás sea más marcado en México que en otros países más desarrollados, donde el nivel de desigualdad con relación a la renta es menos pronunciado. Consideremos de nuevo la historia de los taxistas que bloquearon los accesos a la ciudad como protesta. Vernik (1998) realizó un estudio sobre la acogida que tuvo en la audiencia la historia que, de similares características que la anterior, emitió Televisa. Él encontró que, mientas que los telespectadores de clase media compartían la misma indignación que Televisa y Televisión Azteca en relación con el inconveniente causado a los conductores bloqueados, los de clase trabajadora no estaban tan de acuerdo con esta visión: "todos tienen el derecho de ser escuchados", decía un telespectador, "todos tienen el derecho a que se les ponga un poquito de atención" (171). Este punto de vista raramente tiene lugar en la representación que Televisa hace de la voz del pueblo.

El tratamiento de los temas económicos constituye otro buen ejemplo. En algunos aspectos, y al igual que la cobertura de otros temas, es más abierto hoy en día. En 1994, por ejemplo, las declaraciones positivas sobre asuntos económicos en los teleinformativos, superaron a las negativas en una proporción de 9 contra 1; en 1998/99 la misma proporción era inversa 3 contra 1 . No obstante, en los programas existió una fuerte inclinación hacia el apoyo de las políticas públicas de corte neoliberal favorecidas por la clase media, al mismo tiempo debatidas apasionadamente en un contexto en el que el Gobierno planeaba abandonar a la industria bancaria. En un sentido se reflejaba un incremento de la presencia de hombres de negocios en los informativos de un $2 \%$ en 1994, a un $8.2 \%$ en 1998/99: Estos empresarios eran a veces más francos sobre el estado de la economía de lo que los miembros del Gobierno lo habían sido en una época anterior, pese a que también secundaban las políticas neoliberales.

Finalmente, existe el peligro de que, una vez que el periodo de transición termine, la tendencia a realizar programas de entretenimiento en detrimento de contenidos políticos crezca de forma significativa. Hoy en día, la democracia es algo nuevo en México y, en importantes partes de la sociedad, genera un considerable interés. En este contexto, los locutores están proporcionando todavía cuotas razonables de atención a los asuntos públicos en los contenidos. Los informativos de Televisión Azteca, por ejemplo, son de una hora de duración, pero fueron ampliados en 15 minutos durante las elecciones legislativas de 1997 para proporcionar más tiempo a la cobertura de las mismas. Las emisiones locales y matinales tienden también a tener contenidos más políticos que otras de las mismas características en Estados Unidos de América -EEUU- (quizá los europeos estarían menos impresionados). Sin embargo, en un contexto histórico diferente, locutores comerciales podrían elegir de forma diferente.

\section{CONCLUSIÓN}

El periodismo popular, entendido como aquel que, en la búsqueda de una audiencia masiva, mezcla entretenimiento e informativos, se inclina hacia lo visual, emotivo y sensacionalista, y favorece la experiencia personal de la gente corriente, ha existido de diferentes formas. Ha sido completamente apolítico en su contenido explícito, como los productos sensacionalistas superventas americanos, y altamente politizados, como la prensa gráfica laborista en la Alemania de los años '20 y principios de los '30 (Hardt, 1996), o el británico Daily Mirror en los ‘ 40 (Smith, 1975) 3. Ha estado a la derecha y a la izquierda del espectro ideológico. En algunos casos, está relativamente lejos del periodismo tradicional, y en otros no. Podemos decir que el periodismo tradicional en EEUU y el norte de Europa, donde la prensa de circulación masiva se desarrolla en el siglo XIX, ha sido siempre profundamente determinado por las tradiciones del periodismo popular.

En algunos casos, y de diferentes formas, el periodismo popular ha contribuido a la apertura de la esfera pública democrática. Ha promovido el interés popular por la política, en parte mostrando los asuntos políticos en términos más accesibles al público $4 ; \mathrm{Ha}$ forzado a los actores políticos de la cúpula a dirigir las inquietudes del público, concediendo un espacio para los movimientos y opiniones populares, y ha simbolizado su relevancia en el proceso político. En otros casos, y en otro sentido, ha tenido más consecuencias negativas, desalojando el contenido político de los noticiarios, distorsionando la agenda política, marginando y estereotipando a grupos sociales concretos, o proporcionando un espacio de propaganda por el cual los propietarios de los medios pueden modelar la opinión pública. La dirección en la que los efectos del periodismo popular camina, depende de una serie de factores, entre los que se incluyen la coyuntura histórica y la estructura del sistema mediático. Realmente, cualquier concepción que adopte una relación de "suma cero" entre la "sensacionalización" o el periodismo popular ${ }^{5}$, por una parte, $\mathrm{y}$

3. Otros casos interesantes, donde el periodismo popular era menos explícitamente político, pero tenía relación con movimientos y cultura política populares, son los de Police Gazette en los EEUU de la década de 1830 (Schiller, 1981) y The Sun en la de 1860 y 1870 (Steele, 1993).

4. Gripsrud (1992). Véase mis discusiones sobre New York Daily News (1986) y los teleinformativos matinales (1994).

5. A veces el término "sensacionalización" parece implícitamente ser definido en términos de esas características del periodismo popular, las cuales son negativas desde el punto de vista del proceso democrático, así que el argumento por el cual la "sensacionalización" es mala para la democracia, se convierte esencialmente en tautológico. Esto no me parece una acción analítica muy útil. 
la política democrática, por otro, es demasiado simple, al igual de otra concepción que asuma la perfecta harmonía entre éstos.

En el caso mexicano, el cambio más dramático hacia el periodismo televisivo popular ha tenido lugar en el contexto de una importante apertura democrática, y tiene que ser interpretado como parte significativa de este proceso. Al mismo tiempo, es un desarrollo altamente contradictorio, que refleja tensiones entre imperativos comerciales o económicos y el criterio periodístico, entre diferentes intereses sociales observables en México, y entre los distintos elementos de una cultura política considerablemente fluida. La crítica del nuevo periodismo mexicano no debería centrarse en el periodismo popular per se, el cual es parte de cualquier sistema mediático en democracia, sino en las formas específicas en las que es desplazado a posiciones problemáticas, por presiones comerciales, desequilibrios del poder social y elementos de la cultura política y periodística, que van en contra de la democracia.

\section{BIBLIOGRAFÍA}

BARRERA, Idalia (1999): "Cumple un año de asumir reto". En Reforma,20, Enero, E1.

Craig, Ann L. y Cornelius WAYNE (1981): "Political Culture in Mexico: Continuities and Revisionist Interpretations". En Gabriel Almond y S. Verba (Eds.): The Civic Culture Revisited: An Analytic Study. Boston: Little, Brown \& Company.

Delgado, Alvaro (1998): "Vocero de los gobiernos en turno, Zabludovsky sirvió casi tres décadas a los intereses de un sistema en declive". En Proceso, 25, Enero, 6-11.

Bucci, Eugênio (1993): "Da Pancadaria Explícita à Violência Invisivel". En E. Bucci: O Peixe Morre Pela Boca: Oito Artigos Sobre Cultura e Poder. São Paulo: Scritta.

Epstein, Jack (1993): "News Agressivo: Aqui Agora and South America's Passionate, Controversial New Journalism”. En Columbia Journalism Review, 32, Nov-Dec, 39-41.

Fadul, Ligia Maria, Solís Leree, Beatriz y Fatima Fernández Chrislieb (1996): "La Pantalla Televisiva Se Pinta de Rojo". En Nexos, Agosto, 1.

FISKE, John (1992): "Popularity and the Politics of Information". En P. DAHLGREN and C. SPARKS (Eds.): Journalism and Popular Culture. London: Sage.

GALAN, José Luis (1997): "Arremete la Asamblea contra la violencia en la television". En El Economista, Octubre 31.

GonZÁLEZ MolinA, G. (1987): "Mexican Television News: The Imperatives of Corporate Rationale". En Media, Culture and Society, 9, 159-187.

GRIPSRUD, Jostein (1992): "The Aesthetics and Politics of Melodrama". En P. DAHLGREN y C. SPARKS (Eds.): Journalism and Popular Culture. London: Sage.

Hallin, Daniel C. (1994): Dos Instituciones, Un Camino: Television and the State in the 1994 Mexican Election. Paper presentado en la reunión anual de la Asociación Americana de Estudios Latinoamericanos. Washington, D.C.

Hallin, Daniel C. "Próximanmente. Media, Political Power and Democratization in Mexico". En J. CURRAN and M. PARK (Eds.): De-Westernizing Media Studies. London: Routlege.

Hallin, Daniel C. (1994): “'We Keep America on Top of the World': TV News in the Age of Reagan”. En D. Hallin: We Keep
America on Top of the World: Television Journalism and the Public Sphere. London: Routlege.

Hallin, Daniel C. (1986): "Where? Community, Cartography and the Cold War". En R. K. MANOFF y M. SCHUDSON (Eds.): Reading the News. New York: Pantheon.

HardT, Hanno (1996): "Sites of Reality: Constructing Press Photography in Weimar Germany, 1928-33". En The Communication Review, 1(3), 373-402.

KLEIN, Ulrike (1998): "Tabloidized Political Coverage". In the Bild-Zeitung, The Public, V, 79-94.

Lawson, Chappell (1999): Building the Fourth Estate: Democratization and Media Opening in Mexico. Ph.D. dissertation, Stanford University.

MAZA, Enrique (1996): "A las grandes cuestiones nacionales Zedillo responde con vaguedad, con evasivas, con desprecio". En Proceso, Octubre 6, 6-14.

MONSIVÁIs, C. (1997): “'Red news': The crime pages in Mexico". En Mexican Postcards, 148-165. London: Verso.

Moreno Maldonado, Juan (1997): "Ninguna persona del ejecutivo ni segob para cancelar Ciudad Desnuda”. En El Nacional, Noviembre 7.

Ortega Pizaro, F. (1993): ‘En la democratización, la televisión nada tiene que ver': Salinas Pliego; 'nuestro proyecto, entretener': Suárez Vázquez. En Proceso, 26, Julio, 6-13.

Ruiz HarReLl, Rafael (1998): Criminalidad y Mal Gobierno. México: Sansores y Aljure Editores.

Sarmiento, Sergio (1997): "Jaque Mate". En Reforma, Noviembre 7, 22.

SCHILLER, Dan (1981): Objectivity and the News: The Public and the Rise of the Commercial Journalism. Philadelphia: University of Pennsylvania Press.

Servicio Universal de Noticias (1997) ALDF programas TV. México D.F., Octubre 30.

Smith, Anthony C. H.; Con ImmiziRI, Elizabeth y Trevor Blackwell (1975): Paper Voices: The Popular Press and Social Change, 1935-1965. Towtowa, N.J.: Rowman \& Littlefield.

Sparks, Colin (1988): "The Popular Press and Political Democracy". En Media, Culture E Society, 10:2, 209-23.

SPARKS, Colin (1992): "Popular Journalism: Theories and Practice". En P. DAHLGREN and C. SPARKS (Eds.): Journalism and Popular Culture. London: Sage.

STEELE, Janet E. (1993): The Sun Shines for All : Journalism and Ideology in the Life of Charles A. Dana. Syracuse, N.Y.: Syracuse University Press.

Trejo Delarbre, Raúl (1997): "Fuera del aire". En La Cronica, Noviembre 7.

Trejo Delarbre, Raúl (1990): "Periódicos ¿QQuien tira la primera cifra?”. En Cuadernos de Nexos, Junio 1

Trejo Delarbre, Raúl (Ed.) (1988): Las Redes de Televisa. México, D.F.: Claves Latinoamericanas.

Trejo Delarbre, Raúl (Ed.) (1985): Televisa: El Quinto Poder. México, D.F.: Claves Latinoamericanas.

VELA GONZÁLEZ, Rigoberto (1997): "Televisión, decisión responsable". En El Nacional, Noviembre 10.

VERNIK, Esteban (1998): "Comunidades cercadas: la exclusión urbana en la televisión y en la vida”. En N. GARCÍA CANCLINI (Ed.): Cultura y Comunicación en la Ciudad de México, Vol II. México: Universidad Autónoma Metropolitana.

WALLEN, Ruth (1997): Fence or Bridge: Representations of the San Diego/Tijuana Border. Paper presentado en la reunión anual de la Asociación Internacional de Comunicación, Jerusalem. 